\title{
Reliability Improvement of Barrier Thin Films for Organic Light-Emitting Diodes
}

\author{
Kunio Akedo \\ TOYOTA CENTRAL R\&D LABS., Inc., \\ 41-1 Yokomichi, Nagakute, Aichi, 480-1192, Japan
}

\begin{abstract}
We have developed a new silicon nitride ( $\mathrm{SiNx}$ ) multilayer barrier film by plasma-enhanced chemical vapor deposition for an organic light-emitting diode, which consists of SiNx films under two different deposition conditions, that is, a transparent SiNx layer deposited with $\mathrm{NH}_{3}$ gas and an ultra-thin SiNx layer (cap-SiNx) deposited without $\mathrm{NH}_{3}$ gas, which caps over the former layer. This barrier film exhibits high durability under high temperature and high humidity conditions, even at high deposition rates over $100 \mathrm{~nm} /$ minute, because the transparent $\mathrm{SiNx}$ layer, which is easily oxidized under such conditions, is protected by the cap-SiNx layer, and high barrier performance against moisture because pinholes are reduced by adopting multilayer structure. The barrier film also has good transparency because the opaque cap-SiNx layer is sufficiently thin to be almost transparent to the visible light.
\end{abstract}

Keyword: OLED, barrier thin film, silicon nitride, reliability, automobile

\section{Introduction}

Light-emitting diodes based on organic materials [1] are highly attractive candidates for flat-panel displays and the backlights of liquid crystal displays. Recent developments in materials, device structures, and process techniques have enabled the demonstration of organic light emitting diodes (OLEDs) with a high luminous efficiency $[2,3]$ and a long lifetime [4], and red, green, and blue light emitting devices are currently available. Moreover, OLED displays with transparent plastic substrates and barrier thin films are expected to find applications in next-generation wide-area flat-panel displays that are thin, lightweight, and flexible. Barrier thin films are fabricated on both sides of flexible OLED devices in order to prevent moisture ingress directly from the air and moisture penetration through the plastic substrates, which do not have sufficient impermeability to moisture for the OLEDs.
Recently, many barrier films have been reported, such as Barix multilayer barrier films, which are produced by a vacuum evaporation method [5], silicon oxy-nitride films, which are produced by a sputtering method [6], and aluminum oxide films, which are produced by an atomic layer deposition method [7]. Inorganic thin films created by chemical vapor deposition (CVD) are regarded as being well suited to this application because such films offer high barrier performance, good coverage, and high productivity. Indeed, silicon nitride ( $\mathrm{SiNx}$ ) films have already been shown to be well suited as OLED barrier films for encapsulation [8]. In addition to their excellent features, they show low flexibility because they are so fragile that they crack easily when bent. However, this has been improved by adopting new barrier films produced by a CVD method with multilayer structures using thin $\mathrm{SiNx}$ films as barrier 
layers and soft plasma-polymerized films as stress relaxation layers $[9,10]$.

The optically transparent SiNx barrier films applied to the light-emitting side of the OLEDs are fabricated by a radio-frequency (RF) plasma-enhanced CVD method with $\mathrm{SiH}_{4}, \mathrm{NH}_{3}$, and $\mathrm{N}_{2}$ gases at low substrate temperatures below $150^{\circ} \mathrm{C}$. In automotive applications, however, barrier films are required to have high durability despite severe conditions, including high temperatures and humidities. Unfortunately, under such conditions, the transparent $\mathrm{SiNx}$ barrier films, especially when deposited at high deposition rates exceeding 100 $\mathrm{nm} / \mathrm{minute}$, are easily oxidized and their impermeability against vapor is reduced. When SiNx films are deposited without $\mathrm{NH}_{3}$ gas, it is possible to suppress oxidation by hot vapor [8], but the films are not transparent.

In the present study, we developed new SiNx multilayer films for OLEDs that consist of two SiNx layers deposited under different conditions, that is, a transparent $\mathrm{SiNx}$ layer deposited with $\mathrm{NH}_{3}$ gas (tr-SiNx) and a ultra-thin SiNx layer deposited without $\mathrm{NH}_{3}$ gas (cap-SiNx), which caps over the former layers. These new barrier films exhibit high durability under high temperature and high humidity conditions, because the transparent $\mathrm{SiNx}$ layer, which is easily oxidized under such conditions, is protected from hot vapor by a cap-SiNx layer, and show good transparency, because the opaque cap-SiNx layer is sufficiently thin to be almost transparent to visible light.

\section{Experimental}

SiNx oxidation was investigated by Fourier transform infrared spectrophotometer (FT-IR) analysis using a tr-SiNx single-layer film and a cap-SiNx/tr-SiNx multilayer film on Si substrates. The thicknesses of the tr-SiNx and cap-SiNx layers were $200 \mathrm{~nm}$ and $15 \mathrm{~nm}$, respectively. The cap-SiNx layer was made ultra-thin, compared to the tr-SiNx layer, in order to exibit lower optical absorption. The SiNx films were deposited using a parallel-plate RF plasma CVD method with $\mathrm{SiH}_{4}$, $\mathrm{NH}_{3}$, and $\mathrm{N}_{2}$ gases using a SAMCO PD-3802L reactor. The deposition conditions were as follows: $\mathrm{SiH}_{4}$ gas flow rate; $60 \mathrm{sccm}, \mathrm{NH}_{3}$ gas flow rate; 60 $\mathrm{sccm}\left(0 \mathrm{sccm}\right.$ in case of the cap-SiNx layer), $\mathrm{N}_{2}$ gas flow rate; $1,600 \mathrm{sccm}$, pressure; $106 \mathrm{~Pa}$, input
RF power; $0.22 \mathrm{~W} / \mathrm{cm}^{2}$, and substrate temperature; $100^{\circ} \mathrm{C}$. Under this condition, the deposition rate was approximately $100 \mathrm{~nm} /$ minute. The multilayer film was fabricated by changing the $\mathrm{NH}_{3}$ gas flow rate from $60 \mathrm{sccm}$ to $0 \mathrm{sccm}$ sequentially during deposition. When the $\mathrm{NH}_{3}$ gas flow rate was changed, slight plasma confusion occurred, but did not affect the film quality because the change in the total gas flow rate was only $3.5 \%$. FT-IR spectrum measurements were carried out in the range of $500-4,000 \mathrm{~cm}^{-1}$ with an FT-IR spectrometer (Nicolet Avatar 360 FT-IR).

\section{Results and Discussion}

Figure 1 shows FT-IR spectra before and after a storage test in an atmosphere of $65^{\circ} \mathrm{C}-95 \% \mathrm{RH}$ for 150 hours. Before the storage test, as reported by Kubota et al., three peaks related to the SiNx film were observed. ${ }^{8}$ The peak at $845 \mathrm{~cm}^{-1}$ is generated by the $\mathrm{Si}-\mathrm{N}$ stretching mode, which is the main peak of the SiNx film, and the peaks at $2,150 \mathrm{~cm}^{-1}$ and
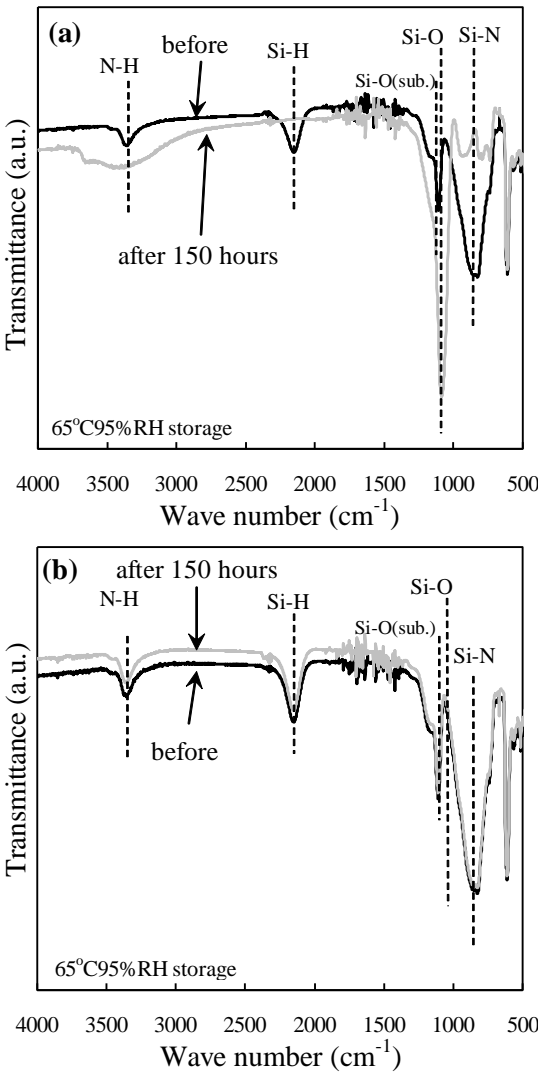

Fig. 1. FT-IR spectra before and after the storage test in atmosphere of $65{ }^{\circ} \mathrm{C}-95 \% \mathrm{RH}$ for 150 hours: (a) a tr-SiNx single-layer film, (b) a cap-SiNx / tr-SiNx multilayer film.

$3,350 \mathrm{~cm}^{-1}$ are the $\mathrm{Si}-\mathrm{H}$ and N-H stretching modes, respectively, which are undesirable peaks for an ideal SiNx film. After the storage test of the 


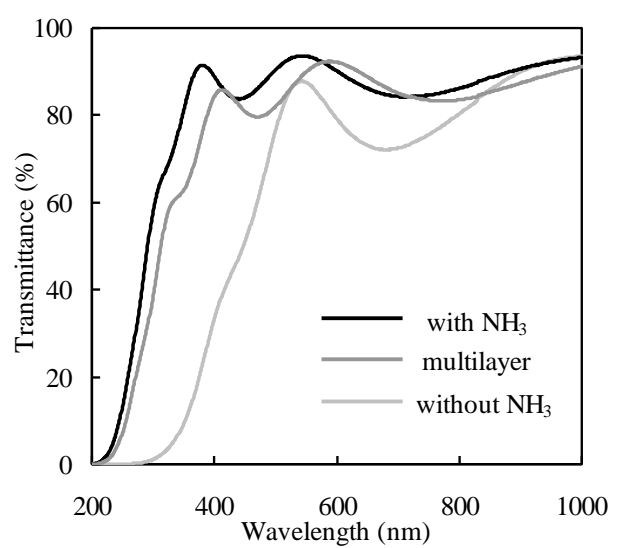

Fig. 2. Optical transmission spectra of the SiNx film deposited with and without $\mathrm{NH}_{3}$ and the cap-SiNx/tr-SiNx multilayer film on quartz glass substrates. Thickness of all films is $215 \mathrm{~nm}$.

tr-SiNx film, the Si-N peak disappeared and the peak at $1,080 \mathrm{~cm}^{-1}$ related to the $\mathrm{Si}-\mathrm{O}$ stretching mode appeared, indicating that the SiNx film was entirely oxidized and changed to the silicon oxide (SiOx) film after being stored under high temperature and high humidity conditions. On the other hand, the spectrum of the cap-SiNx/tr-SiNx multilayer film did not change after the storage test. Because the difference between these two cases is the cap-SiNx layer, the cap-SiNx layer protected the tr-SiNx layer from the oxidation by hot vapor.

Figure 2 shows the optical transmission spectra of the SiNx film deposited with and without $\mathrm{NH}_{3}$ and the cap-SiNx/t r-SiNx multilayer film on quartz glass substrates. The optical transmission spectra were measured in the $200-1,000 \mathrm{~nm}$ range with a UV-vis-IR spectrophotometer (Shimadzu UV-3600). The transparency of the SiNx film
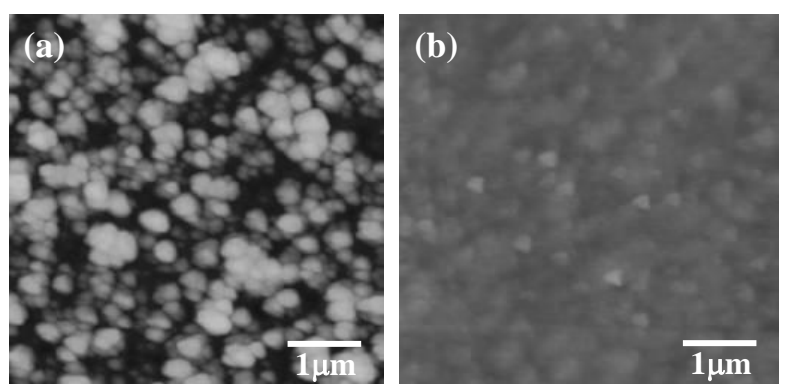

Fig. 3. AFM images of (a) a cap-SiNx film and (b) a cap-SiNx/tr-SiNx film.

deposited with $\mathrm{NH}_{3}$ was more than $80 \%$ in the visible light range, but the $\mathrm{SiNx}$ film deposited without $\mathrm{NH}_{3}$ presented strong absorption in the blue light range and was too opaque to be applied to a barrier film for an OLED. On the other hand, the multilayer film showed almost the same transparency as the tr-SiNx film deposited with $\mathrm{NH}_{3}$. It is considered that this transparency can be maintained because the opaque cap-SiNx layer is sufficiently thin to be transparent to visible light. Thus, the cap-SiNx/tr-SiNx multilayer film has the features of high barrier performance and high transparency.

In order to clear up the cause of high barrier performance against moisture by adopting multilayer structure, we examined an influence of the continuous homo-deposition of the multilayer film on film structures. Figure 3 shows Atomic Force Microscope (AFM) images of (a) a cap-SiNx film and (b) a cap-SiNx/tr-SiNx film on a plastic substrate measured by Digital Instruments Nanoscope IIIa. A cap-SiNx film showed granular structure. Such film generally includes many pinholes, and shows less barrier performance
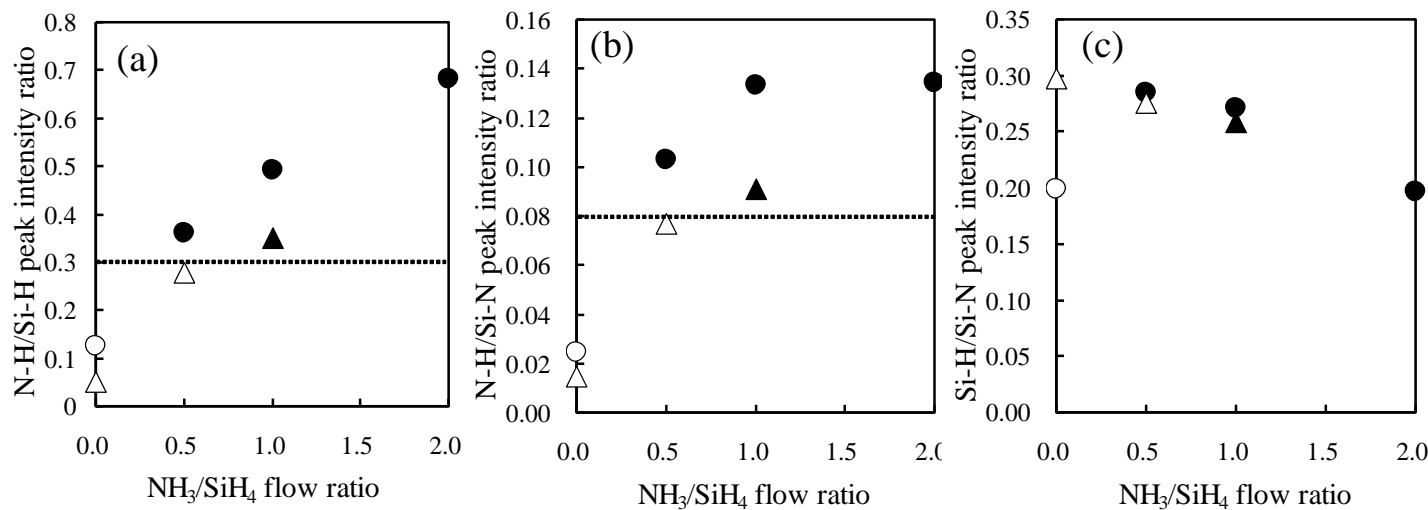

Fig. 4. Peak intensity ratios of (a) N-H / Si-H, (b) N-H / Si-N, and (c) Si-H / Si-N stretching mode in FT-IR spectra of $\mathrm{SiNx}$ films as a function of $\mathrm{NH}_{3} / \mathrm{SiH}_{4}$ gas flow ratio. The samples were fabricated at $100{ }^{\circ} \mathrm{C}$ (open and filled circles) and $180{ }^{\circ} \mathrm{C}$ (open and filled triangles). Open marks mean the samples not oxidized and filled marks mean those oxidized, when they were used in place of the cap-SiNx layer in the multilayer barrier film on Si substrate. 
because moisture easily passes through pinholes. On the other hand, a cap-SiNx/tr-SiNx film showed flat surface and included no pinhole. This fact means a film structure of a cap-SiNx layer changes from granular to flat by adopting the multilayer structure. We considered that the change of the film structure is the cause of high barrier performance against moisture by adopting multilayer structure.

Figure 4 shows peak intensity ratios of the $\mathrm{N}-\mathrm{H} / \mathrm{Si}-\mathrm{H}, \mathrm{N}-\mathrm{H} / \mathrm{Si}-\mathrm{N}$, and $\mathrm{Si}-\mathrm{H} / \mathrm{Si}-\mathrm{N}$ stretching modes in the FT-IR spectra as a function of the $\mathrm{NH}_{3} / \mathrm{SiH}_{4}$ gas flow ratio. The $\mathrm{N}-\mathrm{H} / \mathrm{Si}-\mathrm{H}$ and $\mathrm{N}-\mathrm{H} / \mathrm{Si}-\mathrm{N}$ peak intensity ratios were proportional to the $\mathrm{NH}_{3} / \mathrm{SiH}_{4}$ gas flow ratio and were interrelated with the film oxidation. The border of the oxidation was proved to be 0.3 in $\mathrm{N}-\mathrm{H} / \mathrm{Si}-\mathrm{H}$ and 0.08 in N-H/Si-N. When the over-coated SiNx film has values lower than these, the multilayer barrier film is not oxidized. On the other hand, the $\mathrm{Si}-\mathrm{H} / \mathrm{Si}-\mathrm{N}$ peak intensity ratio showed no relationship with the film oxidation. These facts indicate that the film oxidation was caused by residual $\mathrm{N}-\mathrm{H}$ bonds, not by $\mathrm{Si}-\mathrm{H}$ bonds, in the SiNx films, which were mainly supplied by $\mathrm{NH}_{3}$ gas. Considering that no N-H bond remained after oxidation, the oxidation process is assumed to be triggered by the reaction of hot vapor on $\mathrm{Si}-\mathrm{N}-\mathrm{H}$ bonds to form Si-O bonds and $\mathrm{NH}_{3}$.

\section{Conclusion}

In conclusion, we have developed a cap-SiNx/tr-SiNx multilayer barrier film by plasma CVD for OLEDs for applications in automobiles. This film exhibits high durability under high temperature and high humidity conditions, even at high deposition rates over $100 \mathrm{~nm} /$ minute, because the tr-SiNx layer, which is easily oxidized under such conditions, is protected from hot vapor by a cap-SiNx layer, and high barrier performance against moisture because pinholes are reduced by adopting multilayer structure. The developed film also has good transparency, because an opaque cap-SiNx layer is sufficiently thin to be almost transparent to the visible light. Thus, the multilayer $\mathrm{SiNx}$ barrier film has the features of high reliability, high barrier performance, and high transparency, and makes enables the application of OLED displays in automobiles.

\section{References}

1. C. W. Tang and S. A. Van Slyke, Appl. Phys. Lett., 51 (1987) 913.

2. M. Ikai, S. Tokito, Y. Sakamoto, T. Suzuki, and Y. Taga, Appl. Phys. Lett., 79 (2001) 156.

3. G. He, M. Pfeiffer, K. Leo, M. Hofmann, J. Birnstock, R. Pudzich, and J. Salbeck, Appl. Phys. Lett., 85 (2004) 3911.

4. M. F. Lin, L. Wang, W. K. Wong, K. W. Cheah, H. L. TAM, M. T. Lee, M. H. Ho, and C. H. Chen, Appl. Phys. Lett., 91 (2007) 073517.

5. P. E. Burrows, G. L. Graff, M. E. Gross, P. M. Martin, M. K. Shi, M. Hall, E. Mast, C. Bonham, W. Bennett, and M. B. Sullivan, Displays, 22 (2001) 65.

6. A. Sugimoto, A. Yoshida, T. Miyadera, and S. Miyaguchi, Proc. of The 10th Int. Workshop on Inorganic and Organic Electroluminescence (EL'00), Hamamatsu (2000) 365.

7. A. P. Ghosh, L. J. Gerenser, C. M. Jarman, and J. E. Fornalik, Appl. Phys. Lett., 86 (2005) 223503.

8. H. Kubota, S. Miyaguchi, S. Ishizuka, T. Wakimoto, J. Funaki, Y. Fukuda, T. Watanabe, H. Ochi, T. Sakamoto, T. Miyake, M. Tsuchida, I. Ohshita, and T. Tohma, Journal of Luminescence, 87-89 (2000) 56.

9. K. Akedo, A. Miura, H. Fujikawa, and Y. Taga, Proc. of the Society for Information Display (SID2003), Baltimore (2003) 559.

10. K. Akedo, A. Miura, H. Fujikawa, Y. Taga, Y. Akada, and T. Umehara, Proc. of The 11th Int. Display Workshops (IDW'04), Niigata (2004) 1367. 